\title{
Membrane Reactor System Model for Gas Conversion to Benzene
}

\author{
E. Camilo Corredor, Pallavi Chitta, Milind Deo
}

Department of Chemical Engineering

50 S. Central Campus Dr. Rm 3290

Salt Lake City, UT 84112-9203

\section{KEYWORDS}

Gas to liquid (GTL), methane, benzene, membrane reactor, Aspen Plus, CAPE-OPEN, nonoxidative, dehydroaromatization

\begin{abstract}
In the direct nonoxidative conversion of methane gas to liquid chemicals, it has been shown that continuous removal of produced hydrogen is a way to overcome the thermodynamic limit of low equilibrium methane conversion. A plug-flow, isothermal membrane reactor model was developed for the conversion of methane gas to aromatics over Mo/H-ZSM5 and integrated in an Aspen Plus process model using COCO (cape-open to cape-open) Simulator. Parameters such as reaction rate constants and equilibrium coefficients required by the model were obtained using experimental data. The reactor employs a simplified reaction network whose product distributions agree well with other models and published results. Damkohler number of 0.5 and a dimensionless hydrogen removal parameter $\delta$ of 10 were found to be the optimum parameters for benzene selectivity. The reactor model being embedded in the process allows for more detailed exploration of the impact of reactor parameters on the process as a whole. Methane conversion remains at $10.9 \%$ and $20 \%$ for each case with or without recycle. Benzene molar flow increases
\end{abstract}


by $72 \%$ for the single pass configuration when $D a=0.5$ and $\delta=10$ are used; however, naphthalene molar flow increases by $215 \%$.

\section{INTRODUCTION}

Our rapidly growing population imposes a large demand on products of the organic chemical industry, the manufacture of which heavily relies almost entirely on petrochemicals. Additionally, developing technologies in unconventional oil recovery are producing great amounts of oil and gas from previously inaccessible rock formations. ${ }^{1}$ The U.S. Energy Information Administration reports that gross natural gas withdrawal for January 2015 was 2,840 Bcf. Meanwhile, storage increased from 825 Bcf in April 2014 to 1,476 Bcf in April 2015. ${ }^{2}$ With the depletion of conventional petroleum reserves and the abundance of natural gas, methane is slated to become the most important hydrocarbon feedstock for synthesizing fuels and chemicals.

Benzene is an important petrochemical precursor to chemicals such as ethylbenzene, cumene, and cyclohexane. These are further processed make dye, detergent, adhesives, textiles, rubber, plastics, and more. The prevalence of benzene in such a wide variety of industries is such that worldwide benzene demand is often used as an economic bell-weather. Recent reports have demonstrated an increasing demand for benzene spurred by industrial development in the Eastern hemisphere, The demand is projected to grow at a rate of $3 \%$ per year reaching 50 million metric tons by $2018 .^{3}$

\section{Current Benzene Production Methods}

Most ( $\sim 95 \%)$ of the world benzene supply is currently petroleum derived using one of three main methods: catalytic reforming, toluene hydrodealkylation, and from steam cracking of naphthas to produce pyrolytic gasoline. ${ }^{4}$ 
Catalytic reforming produces approximately $30 \%$ of the world benzene supply. ${ }^{5}$ Aromatic molecules are produced from dehydrogenation of cycloparaffins, dehydroisomerization of alkyl cyclopentanes, and cyclization and subsequent dehydrogenation of paraffins. ${ }^{5}$ Toluene hydrodealkylation contributes $25 \%$ - $30 \%$ of the world benzene supply. Toluene is mixed with a hydrogen stream and passed through a catalytic reactor using chromium or molybdenum oxide. ${ }^{6}$ The remaining benzene produced via the pyrolytic gasoline route constitutes steam cracking of heavy naphthas or light hydrocarbons, such as propane or butane, are used to make ethylene. The by-product of this process is a drip oil typically composed of $65 \%$ aromatics, which contain approximately $50 \%$ benzene. $^{7}$

\section{State-of-the-art in Natural Gas Conversion}

Much work has been done in the search for economical ways to convert natural gas methane directly to chemicals. Presently, methane is converted to intermediates such as syngas or methanol and subsequently reacted to form a wide variety products. ${ }^{8}$ The non-syngas routes include oxidative and non-oxidative processes. Oxidative conversion is a coupling process to produce olefins, which can be further converted to liquid hydrocarbons. The oxidative processes are highly exothermic and potentially hazardous. Additionally, these processes require pure oxygen and result in limited selectivity to desired products. In summary, the syngas (indirect) and oxidative coupling (direct) routes have numerous challenges. The direct conversion of methane to aromatics through non-oxidative pathways is an attractive alternative to the above mentioned methods.

Dehydroaromatization (DHA) of methane is one such direct conversion reaction producing aromatic hydrocarbons as well as hydrogen. Molybdenum promoted H-ZSM5 catalysts have been shown to adequately activate the strong $\mathrm{C}-\mathrm{H}$ bonds in methane and aromatize the resulting 
$\mathrm{CH}_{\mathrm{x}}$ species leading to the formation of various aromatics with $\sim 90 \%$ selectivity. ${ }^{9}$ The large quantity of hydrogen byproduct is responsible for thermodynamic limitations resulting in low $(\sim 12 \%)$ equilibrium methane conversion at $973 \mathrm{~K}^{10}$; therefore, a hydrogen removal method must be implemented to achieve industrially acceptable benzene yields. ${ }^{811}$

Recent modeling efforts have focused on the kinetic aspects of the problem such as activation

of methane ${ }^{8}$ and the effect of various parameters on hydrocarbon yield and selectivity. ${ }^{12}{ }^{13}$ Prior modeling efforts constituted a semi-empirical kinetics model and assessing the impact of a hypothetical membrane separator. There is a significant need to develop a semi-empirical model that represents a reactor-membrane assembly and integrate the model with process simulation. Using this integrated model, an analysis of the effect of key parameters on the production process at large may be conducted to more confidently determine feasibility of the technology for industrial use and optimum operating conditions.

The overall modeling methodology is described in Figure 1.

\section{REACTOR MODEL}

A membrane reactor model was created in Matlab R2013b and interfaced with Aspen Plus v8.8 as a CAPE-OPEN User Model. The reactor scheme in Matlab consists of isothermal 1D differential plug flow reactor equations describing a simplified set of three equilibrium reactions which have been shown to adequately describe catalytic methane conversion to aromatics. ${ }^{14}$ A dimensionless mole balance equation (Eq. 1) including Fickian hydrogen transport through a membrane much thinner than the reactor diameter has been developed by Li et al. and here is used on the reaction side. ${ }^{11}$ 


$$
\frac{1}{D a} \frac{d \phi_{i}}{d \xi}=\sum_{j=1}^{n} \lambda_{i j} \beta_{j} f_{j}(K, p)-\delta \alpha_{i}\left(y_{i t}-y_{i s}\right)
$$

Inputs to the model are the feed composition and flow rate, as well as Damkohler number and $\delta$, which are qualitatively defined as the ratio of reactant conversion rate to reactant inlet rate, and the ratio of permeation rate to reaction rate, respectively. ${ }^{11}$

$$
\begin{aligned}
& D a=\frac{L k_{1}}{J_{C H 4, o}} \\
& \delta=\frac{4 P_{H 2} p}{d l k_{1}}
\end{aligned}
$$

With both of these parameters, key variables such as reactor and membrane dimensions, and reaction conditions are taken into account.

Experiments using 3\% Mo/H-ZSM5 were carried out under the conditions in Table 1. Equilibrium constants for the reactions in Table 2 were calculated using the van't Hoff equation and confirmed using a Gibbs minimization reactor in Aspen Plus. Aspen will calculate phase and chemical equilibrium such that Gibbs energy is minimized and return the results as the reactor outlet stream. This stream composition is then used to calculate the equilibrium constant $K_{i}$ for each reaction $i$ as

$$
K_{i}=\frac{[C]^{a}[D]^{b}}{[A]^{c}[B]^{d}}
$$

Where the bracketed terms are the species concentration in $\mathrm{mol} / \mathrm{m}^{3}$, and the exponent is the corresponding stoichiometric coefficient in reaction $i$.

The reactor simulations were carried out isothermally at $973 \mathrm{~K}$ and 1.01 bar. Rate law expressions (Eqs. 5-7) were placed in a Matlab function file with mole balance expressions as the right hand side of the system of differential equations and solved using the solver ODE45. Concentrations used in the rate law for each reaction were calculated assuming an ideal gas. 


$$
\begin{aligned}
& f_{1}=\left(\frac{1}{C_{C H_{4}, o}}\right) * \beta_{1} * C_{C H_{4}} *\left(1-\frac{C_{H_{2}}^{2} * C_{C_{2} H_{4}}}{K_{1} * C_{C H_{4}}^{2}}\right) \\
& f_{2}=\left(\frac{1}{C_{C H_{4}, o}}\right) * \beta_{2} * C_{C H_{4}} *\left(1-\frac{C_{H_{2}}^{2} * C_{C_{2} H_{4}}}{K_{2} * C_{C H_{4}}^{2}}\right) \\
& f_{3}=\left(\frac{1}{C_{C H_{4}, o}^{2}}\right) * \beta_{3} * C_{C_{6} H_{6}} * C_{C_{2} H_{4}} *\left(1-\frac{C_{H_{2}}^{3} * C_{C_{10} H_{8}}}{K_{2} * C_{C_{6} H_{6}} * C_{C_{2} H_{4}}^{2}}\right)
\end{aligned}
$$

As can be seen from the mole balance expressions (Eqs. 8-12), the effect of $\delta$ becomes more pronounced as the species mole fraction increases, assuming all permeabilities are equal. In this model it is assumed that the membrane is permeable only to hydrogen. As such, all other permeabilities are set to zero. It is assumed that a carrier gas completely removes all permeated hydrogen in order to maximize the partial pressure driving-force and increase transport through the membrane.

$\frac{d \phi_{C H 4}}{d \xi}=D a *\left(-2 * f_{1}-\delta *\left(\frac{P_{C H_{4}}}{P_{H_{2}}}\right) * y_{C H_{4}}\right)$

$\frac{d \phi_{H 2}}{d \xi}=D a *\left(2 * f_{1}+3 * f_{2}+3 * f_{3}-\delta *\left(\frac{P_{H_{2}}}{P_{H_{2}}}\right) * y_{H_{2}}\right)$

$\frac{d \phi_{C 2 H 4}}{d \xi}=D a *\left(f_{1}-3 * f_{2}-2 * f_{3}-\delta *\left(\frac{P_{C_{2} H_{4}}}{P_{H_{2}}}\right) * y_{C_{2} H_{4}}\right)$

$\frac{d \phi_{C 6 H 6}}{d \xi}=D a *\left(f_{2}-f_{3}-\delta *\left(\frac{P_{C_{6} H_{6}}}{P_{H_{2}}}\right) * y_{C_{6} H_{6}}\right)$

$\frac{d \phi_{C 10 H 8}}{d \xi}=D a *\left(f_{3}-\delta *\left(\frac{P_{C_{10} H_{8}}}{P_{H_{2}}}\right) * y_{C_{10} H_{8}}\right)$

Table 3 lists a sample set of variables which are used to calculate Da and $\delta$. Alternatively, Da and $\delta$ may be specified directly. Temperature, pressure, and rate constant are fixed. By performing a species balance on hydrogen we may calculate its length averaged flux through the membrane and, when assuming a hydrogen partial pressure, can be used in conjunction with the membrane thickness via Eq. 13 to determine permeability. 


$$
J_{H_{2}}=\frac{P_{H 2}}{l}\left(p_{H_{2}, t}-p_{H_{2}, S}\right)
$$

Of course in practice it is rather the membrane permeability which determines hydrogen flux and the model is able to handle either as an input given that membrane thickness is defined. This configuration allows the user to vary hydrogen flux and the model will return the permeability required to produce that flux. This may be useful during membrane design.

\section{MODEL INTEGRATION}

There are a handful of options available for including custom models in Aspen Plus simulations. Fortran models may be created but Excel spreadsheets may also be used in the User2 unit operation to develop and test the model in Excel without iterative compiling and linking that would be performed in a native Aspen unit. ${ }^{15}$ The Excel model may use all built-in commands and macros but this becomes cumbersome when attempting to solve systems of differential equations.

As of early 2015, there is no method for directly implementing Matlab models with Aspen Plus simulations; however, the Cape-Open to Cape-Open (COCO) Simulator v3.0 may be utilized as an intermediary between these two and allow real time communication. COCO offers

a wide variety of Cape-Open compliant unit operations, of particular interest are the "Matlab Unit Operation" and "COFE Flowsheet Unit Operation". Upon installation, these units become available in Aspen's "Cape-Open" library. It would then make sense to simply add a "Matlab Unit Operation" block to the simulation but material streams cannot be connected to the block. This is because the Matlab Unit Operation requires support for the Cape-Open thermodynamic standard version 1.1 on the material stream, currently Aspen Plus v8.8 only implements the older 1.0 version. The work-around to this issue is to rather connect Aspen material streams to a “COFE Flowsheet Unit Operation”. 
The heterogeneous membrane reactor model was inserted within this unit and material streams were connected as usual. Connectivity to the Aspen model is accomplished by importing thermodynamics from the feed stream. Upon execution of the simulation, the Cape Open Flowsheet Environment's (COFE) feed streams are populated with the connected Aspen stream data, the Matlab code is executed, and COFE's product stream data are transferred to the connected Aspen streams.

Diagrams of the process model implemented in Aspen are shown in Figures 2 and 3. A production target of $190 \mathrm{Mbbl}$ benzene/yr was set, which is approximately $0.5 \%$ of the total U.S. benzene production. ${ }^{16}$ For the base case of $D a=1$ and $\delta=0$, fresh methane enters the system at a rate of $1.15 \times 10^{6} \mathrm{kmol} /$ day and is preheated in a shell-and-tube exchanger with recirculating Dowtherm-J. At this point the fresh feed mixes with a recycle stream of unreacted methane and ethylene, preheated with $1.87 \times 10^{5} \mathrm{kmol} /$ day of permeated hydrogen from the membrane reactor. Products are then cooled with three parallel shell-and-tube heat exchangers (this is where the Dowtherm-J picks up heat for the fresh methane) and $581 \mathrm{kmol} \mathrm{naphthalene/day} \mathrm{is} \mathrm{removed.}$ Benzene is removed using a theoretical separator in place of a more rigorous flash vessel or distillation column to save computation time. Light gases may be further separated if needed otherwise they are preheated with the aforementioned hydrogen and recycled to the reactor.

\section{RESULTS AND DISCUSSION}

Process simulations were carried out for the case of pure methane feed as well as ethylene and methane recycle. In all cases, product yields were calculated using the dimensionless mole balances above as a function of $D a$ and $\delta$. Damkohler number ranged from 0.01 to 10 and $\delta$ ranged from 0 to 100 . The conversion of methane $X_{C H 4}$ and selectivity of species $i S_{i}$ are defined as: 


$$
X_{C H 4}=\frac{F_{C H 4, \text { in }}-F_{C H 4, \text { out }}}{F_{C H 4, \text { in }}}, \quad S_{i}=\frac{n_{i} F_{i}}{F_{C H 4, \text { in }}-F_{C H 4, \text { out }}}
$$

By assuming a permeability and membrane thickness, the partial pressure of hydrogen may be used to determine an approximate length-averaged hydrogen flux through the membrane. This length-averaged flux is in agreement with that predicted by Eq. 13.

L. Wang et. al. report $100 \%$ selectivity to benzene over $2 \% \mathrm{Mo} / \mathrm{H}-\mathrm{ZSM} 5$ with $7.2 \%$ methane conversion at $973 \mathrm{~K} .{ }^{17}$ Under similar conditions, and typically using Mo/H-ZSM5 between 950 $\mathrm{K}$ and $1073 \mathrm{~K}$, benzene selectivities are in the range of $50-75 \% .{ }^{18-24}$ Lunsford et al. demonstrated that selectivity to naphthalene was reported to go through a maximum of $20 \%$ selectivity and then decrease to $11 \% .^{25}$

Several sources using a variety of additional metal promoters and catalyst loadings are summarized in Majhi and present selectivities to aromatic hydrocarbons in the range of 75$90 \%{ }^{20}$ Yao performed 21 experiments with temperatures ranging from $913.15 \mathrm{~K}$ to $973.15 \mathrm{~K}$ and various space velocities. At $973.15 \mathrm{~K}$ and $2100 \mathrm{ml} /\left(\mathrm{g}^{*} \mathrm{~h}\right), 90.78 \%$ methane feed, the outlet mole fractions of hydrogen and benzene are $8.8 \%$ and $0.59 \%$, respectively. ${ }^{27}$ The present model, at $1500 \mathrm{ml} / \mathrm{g}$ cat $/ \mathrm{h}$, predicts an outlet hydrogen mole fraction of $8.8 \%$ and $0.89 \%$ for benzene.

Karakaya developed a heterogeneous packed bed model that includes axial diffusive transport $^{12}$ and concurs well with published experimental results ${ }^{27-30}$ but does not consider the effects of hydrogen removal. The present model ignores back-diffusion of reactants, however transport effects are encompassed to an extent in the Damkohler number. The results in this study demonstrate considerable agreement with previous modeling work $^{12,14}$, incorporates the effects of hydrogen removal, and is embedded in a larger process model. Table 4 shows a brief comparison of results with no hydrogen removal. Disagreement between the results in the rightmost column are possibly due to the use of different rate constants. 
Regarding hydrogen removal, it is understood that diminished hydrogen in the system favors production of higher molecular weight hydrocarbons. It is then reasonable to expect the highest yields for $\mathrm{C}_{6}+$ compounds to be obtained at high values for both $D a$ and $\delta$. The model demonstrates that high hydrogen removal and residence time do result in preference for heavier compounds. Under these operating conditions it is predicted that a minimal amount of ethylene should be in the products since it is being consumed to create benzene, and indeed in all cases of considered, the pervasive trend is for ethylene selectivity to exponentially drop with increasing hydrogen removal (see Figure 5). From Figure 4 it is evident that there is what can be thought of as a threshold hydrogen removal factor at $\delta=1$ where methane conversion rises quickly with increasing $\mathrm{Da}$. At this $\delta$ value, methane conversion ranges from $2 \%$ to $73 \%$ at small and large $D a$ values, respectively. Lowering $\delta$ by an order of magnitude results in $20 \%$ maximum methane conversion at $D a=10$.

From Figure 7, at high values of the two dimensionless parameters there is a gradual naphthalene selectivity increase. It has been shown that high $\mathrm{H}_{2}$ permeation rates increase the rate of catalyst deactivation. ${ }^{31}$ On the other hand, Ma suggests adding 3-6\% $\mathrm{H}_{2}$ in the feed to effectively suppress coke formation. ${ }^{18}$ Others suggest a periodic switching operation with $\mathrm{CH}_{4}$ and $\mathrm{H}_{2}$ to recover catalyst activity. ${ }^{29,32,33}$

When reactant transport and reaction rates are of the same order of magnitude and hydrogen is not removed (that is, $\mathrm{Da}=1$ and $\delta=0$ ), the model predicts $10.9 \%$ methane conversion and 93.5\% benzene selectivity for the reactor dimensions in Table 3. At this point the system has not yet reached equilibrium, as the equilibrium methane conversion should be $12.4 \%$. The required Damkohler number to see this equilibrium in the model would be 100 . Table 5 lists the methane conversion and species selectivities at four values of $D a$. A mere increasing of residence time 
without hydrogen removal will drop benzene selectivity to $42.3 \%$, and as can be seen in Figure 6 , there is a clear region where naphthalene begins to be the preferred product. Taking these effects into account, it seems that the optimum parameters for benzene production are $D a=0.5$ and $\delta=10$. This combination maximizes conversion while keeping benzene selectivity high and naphthalene selectivity low, and is consistent with the approach of high removal and low methane space velocity. ${ }^{34}$

Table 6 shows a comparison of product yields from the process operating with the base case and the presumed best case for benzene production. The effect of recycling all unreacted methane and ethylene is also tabulated. In Table 6, the outlet methane and ethylene are completely recycled, so the total carbon fed to the reactor is the sum of these and fresh methane. The hydrogen entry in the table does not include permeated hydrogen.

Methane conversion remains at $10.9 \%$ and $20 \%$ for each case with or without recycle. Benzene molar flow increases by $72 \%$ for the single pass configuration when $D a=0.5$ and $\delta=10$ are used; however, naphthalene molar flow increases by $215 \%$. The ratio of fresh methane to produced benzene is highest when using recycle ( 0.16 compared to 0.03 for the best case with no recycle) and the molar flow of benzene increases by a factor of more than five when using recycle.

It is interesting to note the differences between the two recycle cases. More than twice as much methane must be recycled in the base case to produce practically the same amount of benzene. The alternate parameters increase the ethylene flow rate by $241 \%$ and increase the naphthalene flow rate by $80 \%$. More in-depth sensitivity studies regarding the process model will be needed to optimize the process. 
This simple kinetic model does not take into account ethane, toluene, polyaromatic hydrocarbons, or coke that are indeed produced experimentally in small amounts and essential for a proper analysis. However, this global scheme consisting of three reactions is representative of major products and is useful for rough model validation and proof-of-concept integration with the process model. Furthermore, kinetic parameters were obtained experimentally and the model agrees well with these and published results. With more experimental runs, more species and reactions may be introduced to increase resolution and accuracy of the model with few modifications.

\section{Acknowledgements}

The authors are grateful for financial support from the United States Department of Energy's Advanced Research Projects Agency - Energy (ARPA-E) under award number DE-AR0000328.

$$
\begin{aligned}
& \text { Nomenclature } \\
& C_{i}=\text { concentration of species } i \\
& D a=\text { Damkohler number } \\
& d=\text { reactor diameter, } \mathrm{m} \\
& f_{j}=\text { dimensionless rate expression for reaction } j \\
& F_{i}=\text { molar flow of species } i, \mathrm{~mol}^{\mathrm{s}} \\
& K=\text { equilibrium constant, } \mathrm{mol} \mathrm{m}^{-3} \\
& J_{C H 4, o}=\text { methane inlet flux, } \mathrm{mol} \mathrm{s}^{-1} \mathrm{~m}^{-2} \\
& J_{H 2}=\text { hydrogen flux, mol s } \mathrm{m}^{-2} \\
& L=\text { reactor length, } \mathrm{m} \\
& l=\text { membrane thickness, } \mathrm{m} \\
& m_{c, i}=\text { mass of carbon in species } i \\
& n_{i}=\text { number of carbon atoms in species } i
\end{aligned}
$$


$P_{H 2}=$ hydrogen permeability, $\mathrm{mol} \mathrm{m}^{-1} \mathrm{~Pa}^{-1} \mathrm{~s}^{-1}$

$p=$ pressure, $\mathrm{Pa}$

$S_{i}=$ selectivity of species $i$

$X_{C H 4}=$ methane conversion

\section{Greek Letters}

$\alpha_{j}=$ permeability ratio in reaction $j$

$\beta_{i}=$ reaction rate constant ratio, $\frac{k_{i}}{k_{1}}$

$\varphi_{i}=$ dimensionless flow rate of species $i$ in reaction side

$\lambda_{i j}=$ stoichiometric coefficient for species $i$ in reaction $j$

$\delta=$ ratio of permeation rate to reaction rate

$\xi=$ dimensionless axial distance

$y_{i t}=$ mole fraction of species $i$ on tube side

$y_{i s}=$ mole fraction of species $i$ on shell side 


\section{REFERENCES}

(1) Kerr, R. A. Science 2010, 328 (5986), 1624.

(2) USDOA. Weekly Underground Natural Gas Storage Report: for week ending April 3, $2015 ; 2015$.

(3) McCloskey, C. Information Handling Services. February 2014,.

(4) Fruscella, W. In Kirk-Othmer Encyclopedia of Chemical Technology; John Wiley \& Sons, Inc., 2000.

(5) Little, D. M. Catalytic Reforming; Pennwell Books,Tulsa, OK, 1985.

(6) Burdick, D. L.; Leffler, W. L. Petrochemicals for the Non-Technical Person; Tulsa, 1983.

(7) Brownstein, A. M. Trends in Petrochemical Technology: The Impact of the Energy Crisis; Petroleum Publishing Company: Tulsa, 1976.

(8) Tang, P.; Zhu, Q.; Wu, Z.; Ma, D. Energy Environ. Sci. 2014, No. 7, 2580.

(9) Tshabalala, T. E. Non-Oxidative Conversion of Methane into Aromatic Hydrocarbons over Molybdenum Modified H-ZSM-5 Zeolite Catalysts, University of the Witwatersrand, 2013.

(10) Zhang, Y.; Wang, D.; Fei, J.; Zheng, X. J. Nat. Gas Chem. 2003, 12 (2), 145.

(11) Li, L.; Borry, R. W.; Iglesia, E. Chem. Eng. Sci. 2001, 56, 1869.

(12) Karakaya, C.; Zhu, H.; Kee, R. J. Chem. Eng. Sci. 2015, 123, 474.

(13) Guo, X.; Fang, G.; Li, G.; Ma, H.; Fan, H.; Yu, L.; Ma, C.; Wu, X.; Deng, D.; Wei, M.; Tan, D.; Si, R.; Zhang, S.; Li, J.; Sun, L.; Tang, Z.; Pan, X.; Bao, X. Science 2014, 344, 616.

(14) Li, L.; Borry, R. W.; Iglesia, E. Chem. Eng. Sci. 2002, 57, 4595.

(15) AspenTech. Getting Started Customizing Unit Operation Models, 2012.

(16) McCafferty, M. Platts, McGraw Hill Financial. Houston, TX June 25, 2014,.

(17) Wang, L.; Tao, L.; Xie, M.; Xu, G.; Huang, J.; Xu, Y. Catal. Letters 1993, 21 (1-2), 35.

(18) Ma, H.; Ohnishi, R.; Ichikawa, M. Catal. Letters 2003, 89, 143. 
(19) Aboul-Gheit, A. K.; El-Masry, M. S.; Awadallah, A. E. Fuel Process. Technol. 2012, 102, 24.

(20) Liu, H.; Yang, S.; Hu, J.; Shang, F.; Li, Z.; Xu, C.; Jingqi, G.; Kan, Q. Fuel Process. Technol. 2012, 96, 195.

(21) Song, Y.; Xu, Y.; Suzuki, Y.; Nakagome, H.; Zhang, Z.-G. Appl. Catal. A Gen. 2014, 482, 387.

(22) Song, Y.; Xu, Y.; Suzuki, Y.; Nakagome, H.; Ma, X.; Zhang, Z.-G. J. Catal. 2015, 330, 261.

(23) Bedard, J.; Hong, D.-Y.; Bhan, A. J. Catal. 2013, 306, 58.

(24) Lacheen, H. S.; Iglesia, E. J. Catal. 2005, 173.

(25) Wang, D.; Lunsford, J. H.; Rosynek, M. P. J. Catal. 1997, 169, 347.

(26) Majhi, S.; Mohanty, P.; Wang, H.; Pant, K. K. J. Energy Chem. 2013, 22, 543.

(27) Yao, B.; Chen, J.; Liu, D.; Fang, D. J. Nat. Gas Chem. 2008, 17, 64.

(28) Korobitsyna, L.; Arbuzova, N.; Vosmerikov, A. Russ. J. Phys. Chem. A 2013, 87, 919.

(29) Cui, Y.; Xu, Y.; Lu, J.; Suzuki, Y.; Zhang, Z.-G. Appl. Catal. A Gen. 2011, 393, 348.

(30) Wong, K. S.; Thybaut, J. W.; Tangstad, E.; Stocker, M.; Marin, G. B. Microporous Mesoporous Mater. 2012, No. 164, 302.

(31) Rival, O.; Grandjean, B. P. A. Ind. Eng. Chem. Res. Guy, Christophe Sayari, Abdelhamid Larachi, Faical 2001, 40, 2212.

(32) Xu, Y.; Lu, J.; Wang, J.; Suzuki, Y.; Zhang, Z.-G. Chem. Eng. J. 2011, 168, 390.

(33) Ohnishi, R.; Kojima, R.; Shu, Y.; Ma, H.; Ichikawa, M. Stud. Surf. Sci. Catal. 2004, 147, 552.

(34) Iliuta, M. C.; Larachi, F.; Grandjean, B. P. A.; Iliuta, I. Ind. Eng. Chem. Res. Guy, Christophe Sayari, Abdelhamid Larachi, Faical 2002, 41, 2371. 


\section{FIGURE AND TABLE CAPTIONS}

\section{Figures}

Figure 1. Overall modeling methodology

Figure 2. Process diagram implemented in Aspen Plus v8.8, part 1

Figure 3. Process diagram implemented in Aspen Plus v8.8, part 2

Figure 4. Methane conversion as a function of Da and $\delta$.

Figure 5. Ethylene selectivity as a function of Da and $\delta$.

Figure 6. Benzene selectivity as a function of Da and $\delta$.

Figure 7. Naphthalene selectivity as a function of Da and $\delta$.

\section{Tables}

Table 1. Reaction and catalyst specifications

Table 2. Reactions and parameters in model

Table 3. Example inputs used to calculate Da and $\delta$

Table 4. Comparison of results with no hydrogen removal

Table 5. Comparison of selectivities and methane conversion at various Da and $\delta$

Table 6. Comparison of base case and that of high benzene selectivity 


\section{FIGURES}

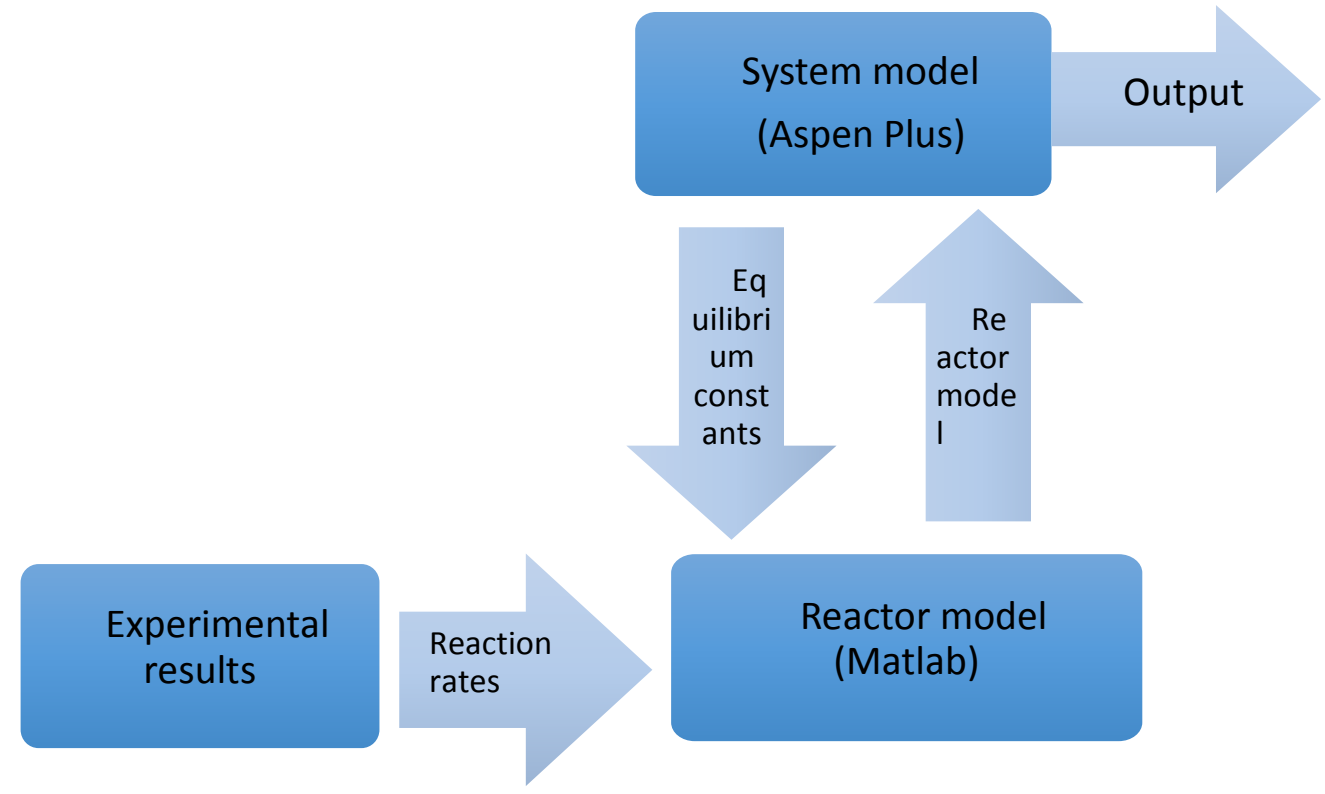

Figure 1. Overall modeling methodology 
Page 18 of 29

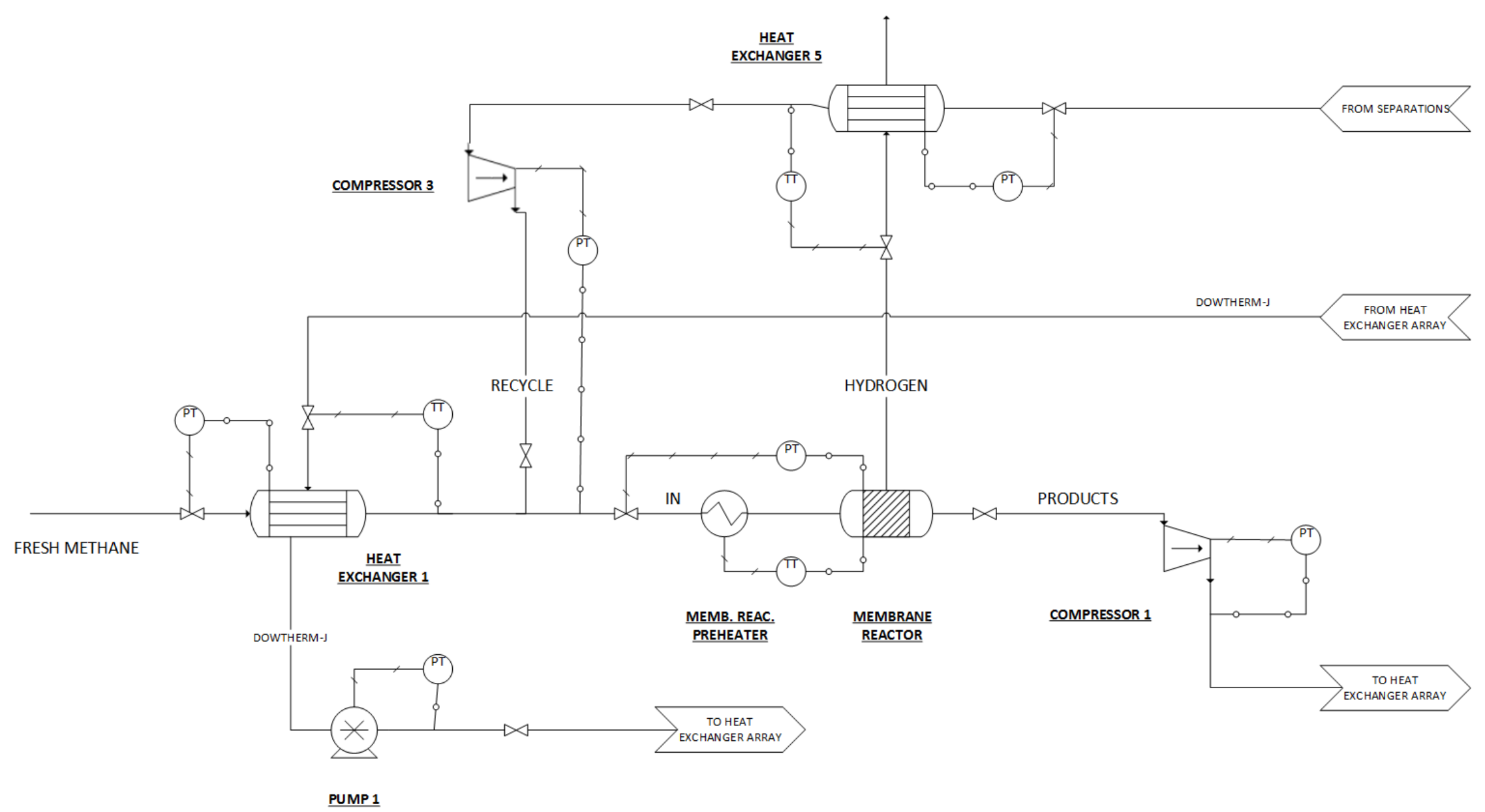

Figure 2. Process diagram implemented in Aspen Plus v8.8, part 1 
Page 19 of 29

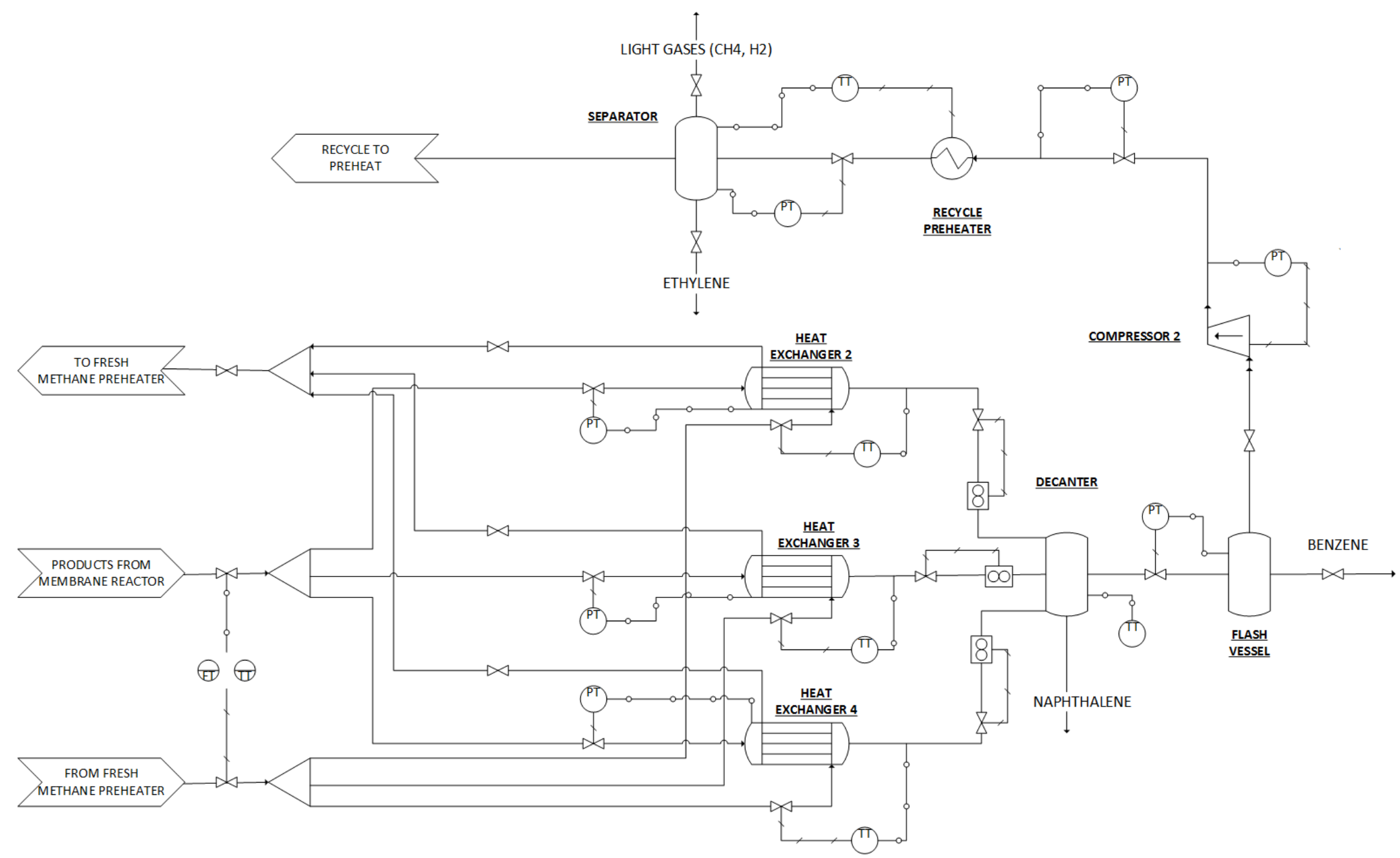

Figure 3. Process diagram implemented in Aspen Plus v8.8, part 2 
Page $\mathbf{2 0}$ of $\mathbf{2 9}$

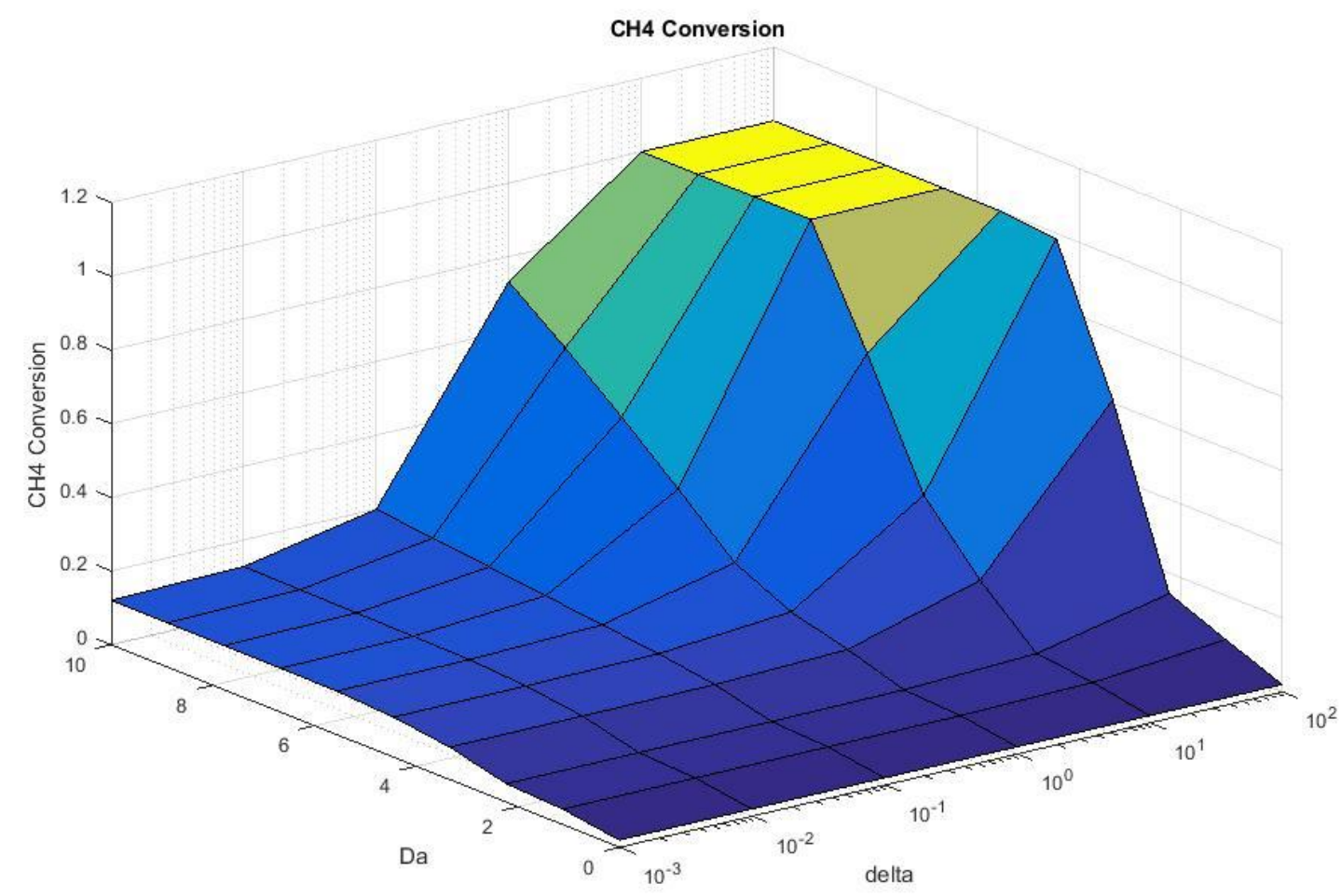

Figure 4. Methane conversion as a function of Da and $\delta$. 
Page 21 of 29

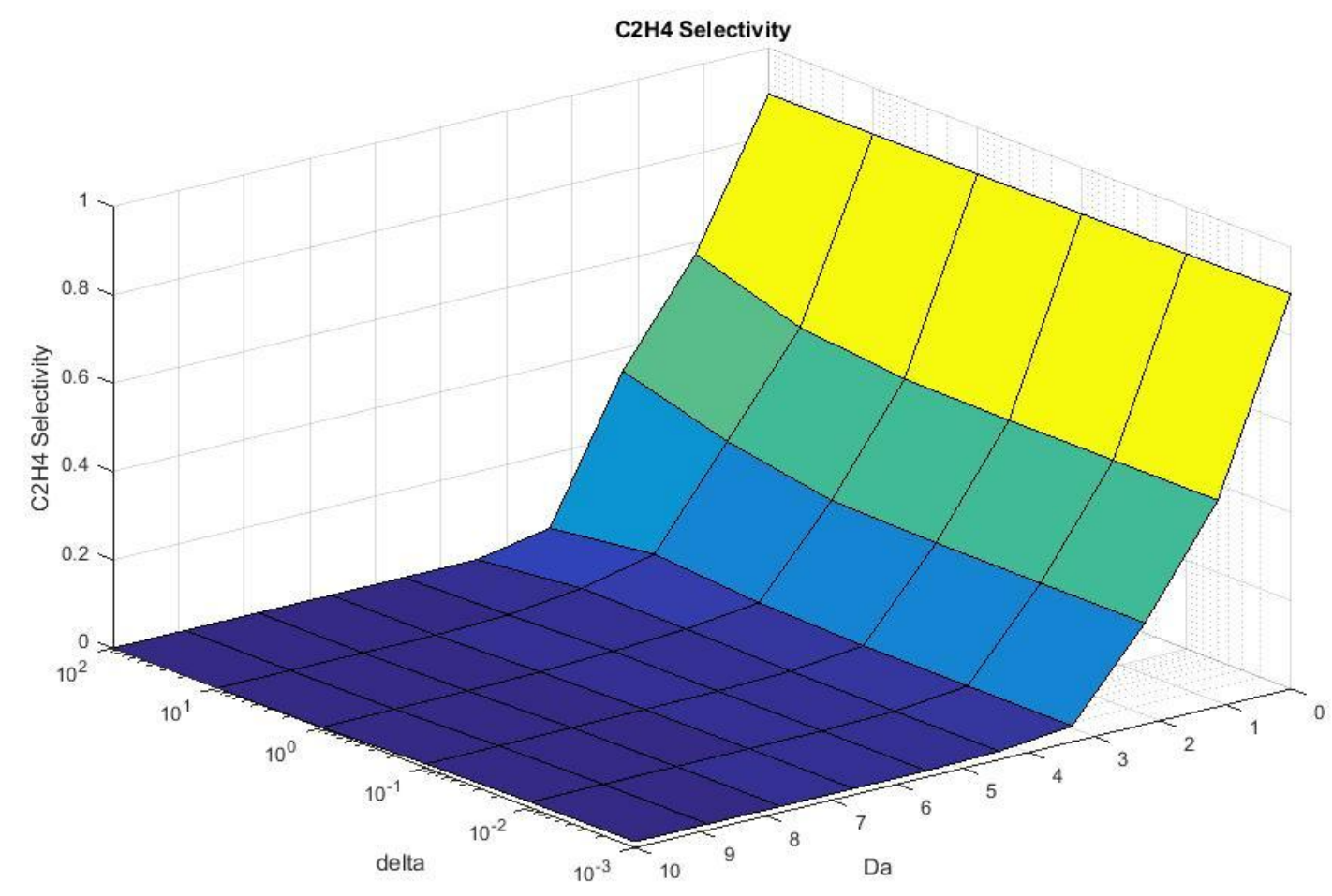

Figure 5. Ethylene selectivity as a function of Da and $\delta$. 
Page 22 of 29

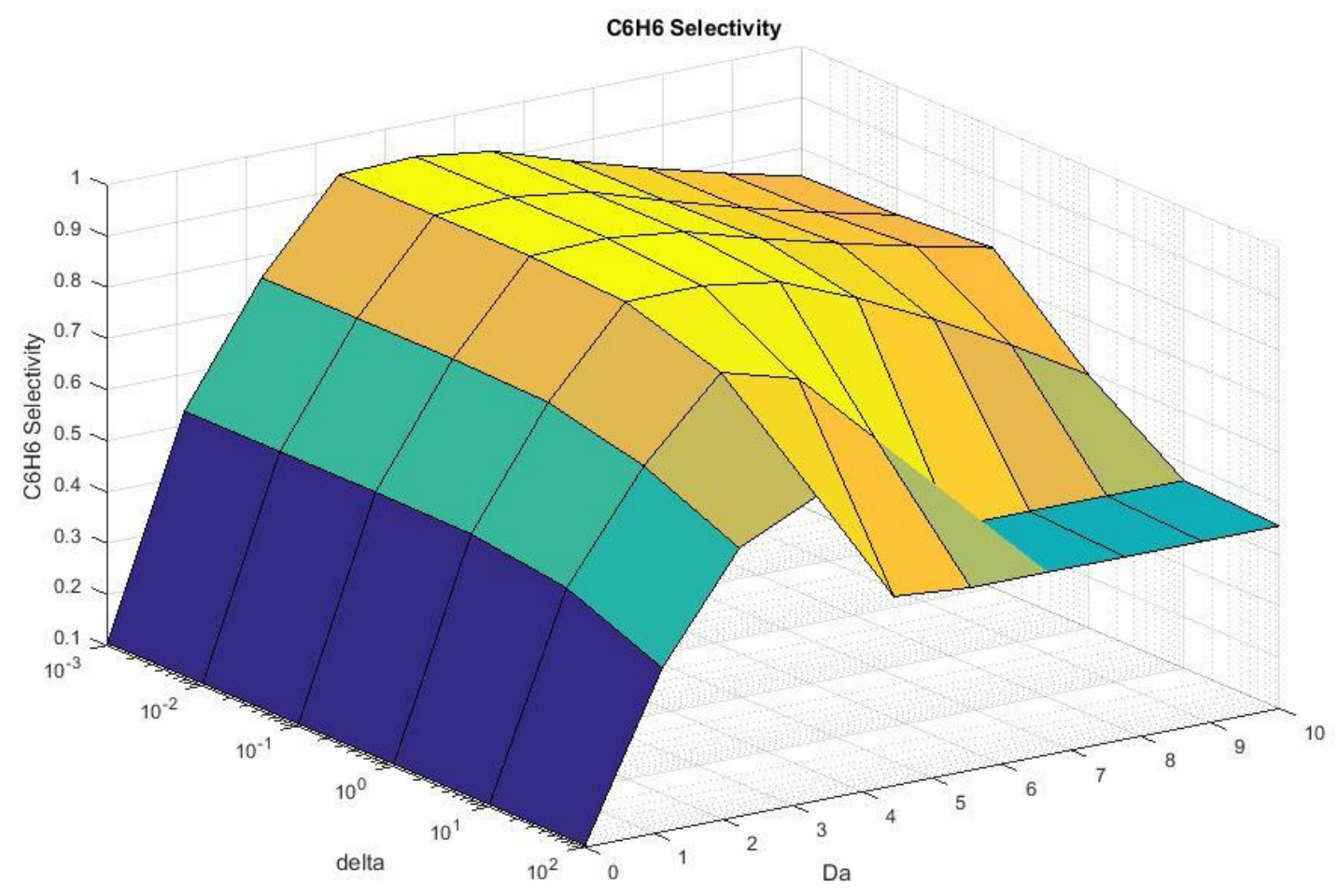

Figure 6. Benzene selectivity as a function of Da and $\delta$. 
Page 23 of 29

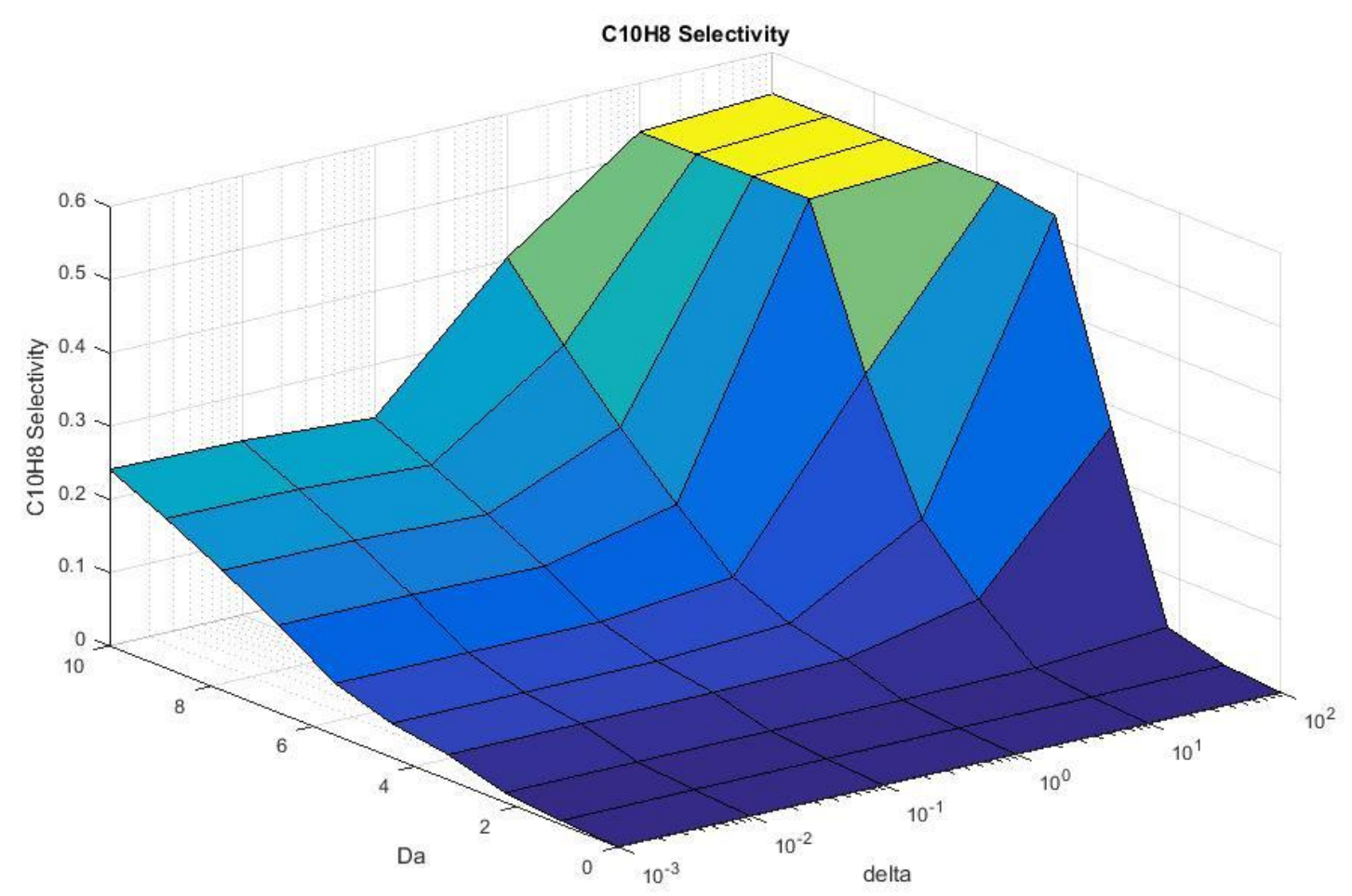

Figure 7. Naphthalene selectivity as a function of Da and $\delta$. 
Table 1. Reaction and catalyst specifications

\begin{tabular}{|c|c|}
\hline Mo/H-ZSM5 (Mo/Al=0.26) & Mo/H-ZSM5 (Mo/Al=0.43) \\
\hline $\begin{array}{l}\text { Amount of catalyst: } 1 \mathrm{~g} \\
\text { Particle size: } 180-250 \mu \mathrm{m} \\
\text { Reactor ID: } 8 \mathrm{~mm} \\
\text { Space velocity: } 1500 \mathrm{cc} / \mathrm{g}_{\text {cat }} / \mathrm{hr}\end{array}$ & $\begin{array}{l}\text { Amount of catalyst: } 0.25 \mathrm{~g} \\
\text { Particle size: } 180-250 \mu \mathrm{m} \\
\text { Reactor ID: } 8 \mathrm{~mm} \\
\text { Space velocity: } 3500 \mathrm{cc} / \mathrm{g}_{\mathrm{cat}} / \mathrm{hr}\end{array}$ \\
\hline $\begin{array}{l}\text { Activation was done in helium } \\
(100 \text { sccm) for } 2 \mathrm{~h} \text { at } 973 \mathrm{~K}\end{array}$ & $\begin{array}{l}\text { Activation was done in helium } \\
(50 \text { sccm) for } 2 \mathrm{~h} \text { at } 973 \mathrm{~K} \text {. }\end{array}$ \\
\hline $\begin{array}{l}\text { Feed: } 85 \% \quad \mathrm{CH}_{4} / \mathrm{Ar} \text { at } 23.6 \mathrm{sccm} \\
\left(\mathrm{CH}_{4} 21.24 \mathrm{sccm}\right) \\
\text { Temperature }\left(\mathrm{T}_{\text {set }}\right): 973 \mathrm{~K} \\
\text { Average pressure: } 1.25 \mathrm{bar} \\
\text { All lines heated up to } \mathrm{T}>453 \mathrm{~K}\end{array}$ & $\begin{array}{l}\text { Feed: } 85 \% \quad \mathrm{CH}_{4} / \mathrm{Ar} \text { at } 13.9 \mathrm{sccm} \\
\left(\mathrm{CH}_{4} 12.5 \mathrm{sccm}\right) \\
\text { Temperature }\left(\mathrm{T}_{\text {set }}\right): 973 \mathrm{~K} \\
\text { Average pressure: } 1.0 \mathrm{bar} \\
\text { All lines heated up to } \mathrm{T}>453 \mathrm{~K}\end{array}$ \\
\hline
\end{tabular}


Table 2. Reactions and parameters in model

\begin{tabular}{|c|l|c|}
\hline Reaction & Rate Constant at 973 K & $\begin{array}{l}\text { Concentration Equilibrium } \\
\text { Constant at 973 K }\end{array}$ \\
\hline $2 \mathrm{CH}_{4}=\mathrm{C}_{2} \mathrm{H}_{4}+2 \mathrm{H}_{2}$ & $7.63 \times 10^{-5} \mathrm{~s}^{-1}$ & $4.03 \times 10^{-4} \mathrm{~mol} \mathrm{~m}^{-3}$ \\
\hline $3 \mathrm{C}_{2} \mathrm{H}_{4}=\mathrm{C}_{6} \mathrm{H}_{6}+3 \mathrm{H}_{2}$ & $5.63 \times 10^{-4} \mathrm{~s}^{-1}$ & $1.85 \times 10^{6} \mathrm{~mol} \mathrm{~m}^{-3}$ \\
\hline $2 \mathrm{C}_{2} \mathrm{H}_{4}+\mathrm{C}_{6} \mathrm{H}_{6}=\mathrm{C}_{10} \mathrm{H}_{8}+3 \mathrm{H}_{2}$ & $1.84 \times 10^{-3} \mathrm{~m}^{3} \mathrm{~mol}^{-1} \mathrm{~s}^{-1}$ & $1.25 \times 10^{5} \mathrm{~mol} \mathrm{~m}^{-3}$ \\
\hline
\end{tabular}


Page $\mathbf{2 6}$ of $\mathbf{2 9}$

Table 3. Example inputs used to calculate Da and $\delta$

\begin{tabular}{|l|l|l|l|}
\hline Variable & Description & Value & Units \\
\hline $\mathrm{J}_{\mathrm{CH} 4 \text {,in }}$ & Initial $\mathrm{CH}_{4}$ flux & $1 \times 10^{-5}$ & $\mathrm{~mol} \mathrm{~s}^{-1} \mathrm{~m}^{-2}$ \\
\hline 1 & Membrane thickness & $1 \times 10^{-4}$ & $\mathrm{~m}$ \\
\hline $\mathrm{L}$ & Reactor length & 0.018 & $\mathrm{~m}$ \\
\hline $\mathrm{d}$ & Reactor diameter & 0.01 & $\mathrm{~m}$ \\
\hline $\mathrm{P}_{\mathrm{H} 2}$ & Hydrogen permeability & $1 \times 10^{-12}$ & $\mathrm{~mol} \mathrm{~m}^{-1} \mathrm{~Pa}^{-1} \mathrm{~s}^{-1}$ \\
\hline
\end{tabular}


Page 27 of 29

Table 4. Comparison of results with no hydrogen removal

\begin{tabular}{|c|c|c|c|c|}
\hline & \multicolumn{2}{|c|}{ Outlet mole fractions } & \multicolumn{2}{|c|}{ Selectivities and methane conversion } \\
\hline & This study & Korobitsyna, et al. ${ }^{28}$ & This study & Iglesia, et al. $^{14}$ \\
\hline Methane & $83 \%$ & $78 \%$ & $12.40 \%$ & $12 \%$ \\
\hline Ethylene & $0.10 \%$ & $0.04 \%$ & $1.20 \%$ & $5 \%$ \\
\hline Benzene & $1.57 \%$ & $1.24 \%$ & $42.30 \%$ & $60 \%$ \\
\hline Naphthalene & $0.04 \%$ & $0.44 \%$ & $56.50 \%$ & $35 \%$ \\
\hline
\end{tabular}


Page $\mathbf{2 8}$ of $\mathbf{2 9}$

Table 5. Comparison of selectivities and methane conversion at various $D a$ and $\delta$

\begin{tabular}{|c|c|c|c|c|c|}
\hline & & Conversion & \multicolumn{3}{|c|}{ Selectivities } \\
\hline $\mathrm{Da}$ & $\delta$ & Methane & Ethylene & Benzene & Naphthalene \\
\hline 1 & 0 & $10.9 \%$ & $1.9 \%$ & $93.5 \%$ & $4.7 \%$ \\
\hline 100 & 0 & $12.4 \%$ & $1.2 \%$ & $42.3 \%$ & $56.5 \%$ \\
\hline 0.5 & 10 & $20.3 \%$ & $6.4 \%$ & $85.8 \%$ & $7.8 \%$ \\
\hline 2 & 100 & $100.0 \%$ & $0.0 \%$ & $45.7 \%$ & $54.3 \%$ \\
\hline
\end{tabular}


Page $\mathbf{2 9}$ of $\mathbf{2 9}$

Table 6. Comparison of base case and that of high benzene selectivity

\begin{tabular}{|c|c|c|c|c|c|c|c|}
\hline & \multirow{2}{*}{$\begin{array}{c}\text { In } \\
\text { Fresh } \\
\text { Methane }\end{array}$} & \multicolumn{5}{|c|}{ Out } \\
\hline & & & Methane & Ethylene & Benzene & Naphthalene & Hydrogen \\
\hline $\mathrm{NR}^{\mathrm{a}}$ Base & $\mathrm{kmol} / \mathrm{day}$ & $1.15 \times 10^{6}$ & $1.03 \times 10^{6}$ & $1.18 \times 10^{3}$ & $1.95 \times 10^{4}$ & $5.81 \times 10^{2}$ & $1.87 \times 10^{5}$ \\
\hline $\mathrm{NR} \mathrm{C}_{6}$ Opt. & $\mathrm{kmol} / \mathrm{day}$ & $1.15 \times 10^{6}$ & $9.18 \times 10^{5}$ & $7.46 \times 10^{3}$ & $3.35 \times 10^{4}$ & $1.83 \times 10^{3}$ & $5.47 \times 10^{4}$ \\
\hline $\mathrm{R}^{\mathrm{b}}$ Base & kmol/day & $1.15 \times 10^{6}$ & $9.53 \times 10^{6}$ & $1.10 \times 10^{4}$ & $1.83 \times 10^{5}$ & $5.53 \times 10^{3}$ & $1.73 \times 10^{6}$ \\
\hline $\mathrm{R} \mathrm{C}_{6} \mathrm{Opt}$. & $\mathrm{kmol} /$ day & $1.15 \times 10^{6}$ & $4.64 \times 10^{6}$ & $3.75 \mathrm{sx} 10^{4}$ & $1.75 \times 10^{5}$ & $9.97 \times 10^{3}$ & $2.78 \times 10^{5}$ \\
\hline
\end{tabular}

${ }^{\mathrm{a}} \mathrm{NR}=$ no recycle. ${ }^{\mathrm{b}} \mathrm{R}=$ recycle 